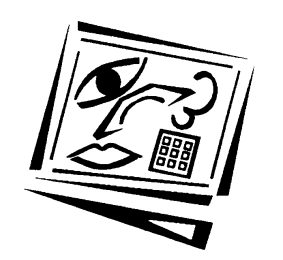

\title{
Implementing clickers to assist learning in science lectures: The Clicker-Assisted Conceptual Change model
}

\author{
Yi-Chun Lin, Tzu-Chien Liu and Ching-Chi Chu \\ National Central University, Taiwan
}

\begin{abstract}
The purposes of this study were twofold. The first aim was to design and develop a clicker-based instructional model known as Clicker-Assisted Conceptual Change (CACC), based on the cognitive conflict approach for conceptual change, to help students to learn scientific concepts. The second aim was to determine the beneficial effects of CACC on students' scientific learning and to explore how CACC might achieve these benefits. Introductory physics was the learning subject, and a mixed-method embedded observation and interview methodology within a quasi-experimental design was used to address the second aim. The participants in this study were 275 first year undergraduates from 6 classes. One class was selected as the experimental group (50 first years) and the other 5 classes were selected as the comparison group (225 first years). The results show that the experimental group who used CACC performed significantly better in the comprehension test than did the comparison group, who used common instructional methods. However, the performance of the calculation test did not differ significantly between the two groups. Several benefits and challenges of CACC are used to explain these findings based on the observational and interview data. Finally, recommendations for future studies on the application of clickers are provided based on this work.
\end{abstract}

\section{Overview}

Interactions in lecture classes are often hampered by various problems, including feedback lag, students' apprehension and only one student being able to express his or her thoughts at any one time (Anderson, Anderson, VanDeGrift, Wolfman \& Yasuhara, 2003), which can result in only a few students in a lecture class getting the opportunity to share their ideas. This leads to most students in this situation being like insular islands, losing their connections with others, which makes it more difficult to engage them in learning activities (Mayer et al., 2009). Clickers, which are seen as a useful tool for solving such problems, have become increasingly widely used in universities, and especially in science education (Kay \& LeSage, 2009a; MacArthur \& Jones, 2008).

"Clickers" (also known as audience response systems, interactive response systems, or other names) is a general term for a tool that consists of a simple handheld signal transmitter, a signal receiver and related software (Liu, Liang, Wang \& Chan, 2003; MacArthur \& Jones, 2008). By using clickers, a teacher can show a multiple-choice question on a large display and all students can anonymously transmit their answers simultaneously. The teacher can then conveniently present all of the students' opinions in an efficient way, for example by displaying the frequencies of specific answers (Hancock, 2010; Kay \& LeSage, 2009a, 2009b; Lantz, 2010). This provides clickers with 
great educational potential to promote student engagement in classroom activities (Draper \& Brown, 2004) and enhance their learning performance (Campbell \& Mayer, 2009; Mayer et al., 2009; Sharma, Khachan, Chan \& O'Byrne, 2005) by enabling every student in a lecture class to share their opinions in a public but non-intimidating way (Beatty, 2004). However, introducing an innovative technology into the classroom does not automatically guarantee that the associated educational benefits will be realised (Liu, 2007). Some studies have shown that the application of clickers does not contribute to better learning performance than does other types of instruction (e.g. Bunce, VandenPlas \& Havanki, 2006; Paschal, 2002). Indeed, the review study of MacArthur and Jones (2008) showed that applying clickers in an inappropriate way (e.g. teachers using them primarily as a tool for taking attendance records and for assessments) may result in students developing a negative attitude towards clickerbased instruction.

The review study by Lantz (2010) found that principles which could enhance the effects of clicker-based instruction are needed, but these are currently still lacking. Therefore, designing and developing a suitable clicker-based instructional model to promote the potential benefits of clickers and hence help teachers achieve their difficult mission is seen as an important research issue (Woelk, 2008).

In science education, enhancing conceptual change among students is an important but difficult task (Limon, 2001), and the cognitive conflict approach is often used to achieve this change (Chan, Burtis \& Bereiter, 1997; Limon, 2001). Lee and Kwon (2001) integrated many definitions of cognitive conflict and ultimately defined it as a perceptual state in which one feels that one's cognitive structure is inconsistent with external information, or one finds that there are some contradictions between the constituents of one's cognitive structure.

In order to promote students' conceptual change by way of cognitive conflict, teachers should teach with several important principles, including the elicitation of students' existing concepts, the presentation of contradictory information, the evaluation of students' conceptual change and the promotion of student motivation (Limon, 2001; Vosniadou \& Vamvakoussi, 2006). Although some of these principles have been used to develop the environment for individual learning (e.g. Liu, 2010), they are very difficult to apply in the large class situation. The potential educational benefits of clickers, such as providing students with opportunities to share their opinions (Beatty, 2004), enhancing classroom interactions (Siau, Sheng \& Nah, 2006) and promoting student engagement (Draper \& Brown, 2004), may help teachers to teach effectively with the principles necessary for cognitive conflict. Therefore, the first aim of the current study was to develop a clicker-based instructional model, known as ClickerAssisted Conceptual Change (CACC), to benefit students' understanding of scientific concepts in the university setting. This model combines the potential educational benefits of clickers and the critical principles needed to elicit conceptual changes using the cognitive conflict approach.

In addition, although several empirical studies have explored the impact of the introduction of clickers into classrooms and provided useful practical suggestions, more empirical studies are needed to further prove the effects of the application of this technology (Mayer et al., 2009). Kay and LeSage (2009a) reviewed 67 peer-reviewed papers on the application of clickers, and reported several limitations of the study methodologies used to investigate the effects of this approach. For example, most studies have focused on exploring students' attitudes towards clickers, while few have 
focused on exploring students' learning performances. Furthermore, most studies have used qualitative methods, with few having used quantitative methods. In recent years, the mixed-methods approach (Creswell \& Plano Clark, 2007) has been accepted as a useful approach for examining the effects of technology-based instruction and exploring how the proposed effects can be achieved (e.g. Liu, Lin \& Kinshuk, 2010; Sung, Chang, Lee \&Yu, 2008). Therefore, the second aim of the current study was to use a mixed-methods approach to determine the effects of CACC on students' learning performance, and to explain the mechanisms underlying the presence or absence of such effects

In universities, introductory physics is considered an important subject and the necessary foundation for the learning of more advanced science, especially for undergraduates who plan to major in science or engineering. However, it is difficult to ensure that students understand the physics concepts presented in such courses (Perkins et al., 2006). Introductory physics was thus considered a relevant subject choice for examining the effects of CACC in science education.

This article introduces the principles for conceptual change by way of cognitive conflict and the corresponding methods for addressing these principles, and discusses the difficulties that may be confronted when using these methods. The CACC, the research questions and the methods used in the current study are detailed, and the findings are reported and discussed. Finally, the limitations of the current work and recommendations for future studies are outlined.

\section{Important principles for enabling conceptual change}

Five important principles for enabling conceptual change and the corresponding methods required to implement these principles were concluded from previous studies on the cognitive conflict approach and are discussed in detail below.

\section{Eliciting students' existing concepts and promoting their awareness thereof}

Promoting students' awareness of their existing concepts is crucial to enabling conceptual change among students (Vosniadou \& Vamvakoussi, 2006). The questioning method, in which a teacher introduces a topic with a question and then leads students to answer it and explain their ideas (Hewson, 1996), is recommended as a useful way of eliciting students' existing concepts and promoting their awareness thereof (Hewson, 1996). Consequently, the questioning method was adopted in the CACC model.

\section{Presenting students with contradictory information to reflect upon}

Presenting students with information that contradicts their existing ideas is a key principle in inducing cognitive conflict. This conflict causes the students to reflect on their existing ideas and thus makes them more likely to accept the correct concepts (Posner, Strike, Hewson \& Gertzog, 1982). Previous studies have proposed several methods of presenting students with contradictory information and asked them to reflect on the weaknesses in their existing concepts. These methods include the use of refutation texts (e.g. Palmer, 2003) and allowing students to observe demonstrations and then leading them to explain the discrepancies between what they think and what they see (e.g. Kearney, 2004). This type of approach was adopted in the CACC instructional model. 


\section{Providing students with sufficient knowledge}

Cognitive conflict is necessary but not sufficient for conceptual change, which ultimately requires students to accept correct concepts. Therefore, after students find that their existing concepts cannot be used to explain a particular phenomenon, it is important to provide them with new, intelligible, plausible and fruitful concepts to enable conceptual change (Posner et al., 1982). The most common method used in the classroom to provide students with sufficient and plausible knowledge is lectures along with appropriate teacher guidance. Therefore, in the CACC model, a lecture given with the aid of a PowerPoint presentation was used to guide students to understand why their existing concepts were correct or incorrect.

\section{Evaluating the degree of change among students before and after instruction}

It is important to evaluate the degree of conceptual change effected by the teaching model among the students (Limon, 2001). If it is found that students do not construct the correct concepts after instruction, remedial instruction should be employed. The questioning method is a convenient way of examining whether students' concepts change; therefore, this method was used in the CACC model.

\section{Enhancing students' motivation to engage in learning activities}

To achieve conceptual change, students must have a high level of motivation to engage in the learning activity (Limon, 2001). Palmer (2005) reviewed various studies and suggested several methods for enhancing students' motivation with regard to achieving conceptual change, such as promoting their active participation in learning activities and providing feedback on their assessments. The aforementioned methods were adopted in the CACC model.

While these principles and corresponding methods may enable conceptual change among students, many obstacles may hinder their effectiveness, especially in large classroom situations. For example, the questioning method is important for addressing two principles necessary for cognitive conflict: (1) eliciting the students' existing concepts and promoting their awareness thereof, and (2) evaluating the degree of conceptual change among the students after instruction. However, it is difficult to apply the questioning method in lecture classes, especially those with a large number of students (Campbell \& Mayer, 2009; Mayer et al., 2009).

Clickers, which have many functions (e.g. providing every student in a class with the opportunity to respond to a question at the same time, computing all of the students' responses and instantly displaying their distributions), have the potential to help teachers to overcome the obstacles that they may encounter when attempting to use cognitive conflict to enable conceptual change. For example, one benefit of clickers is that they can increase students' motivation to engage in the learning activity (Kay \& LeSage, 2009a), which is critical for cognitive conflict. The next section introduces the clicker-based instructional model for conceptual change via the cognitive conflict approach.

\section{CACC}

To implement the five principles necessary for conceptual change and avoid the possible obstacles associated with teaching a lecture class, as mentioned above, this 
work presents an instructional model known as CACC (Figure1). CACC includes four phases, each of which is labelled according to the relevant tasks of the teacher and the student (see Table 1 for details). Appendix A provides an example to show how CACC was applied in the lecture.

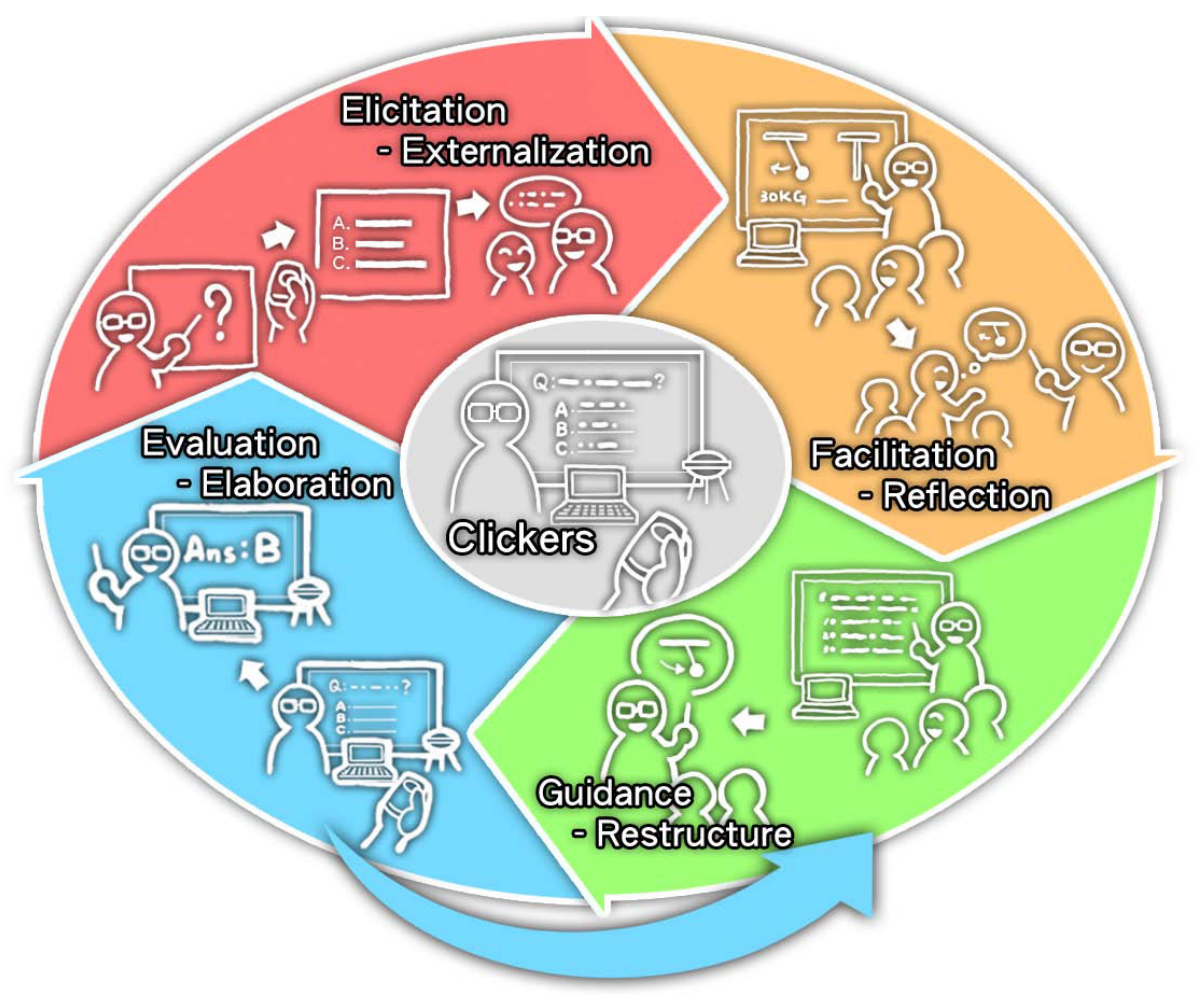

Figure 1: The Clicker-Assisted Conceptual Change (CACC) model

- The elicitation-externalisation phase:

This phase was developed to elicit students' existing concepts and promote their awareness thereof. To achieve these goals, the clickers are used to support questioning and answering activities. After a question related to the target concept is posted on a large display and its meaning is explained by the teacher, the students are asked to provide their responses with their individual transmitters. The distribution of the student responses (without answers) is then immediately displayed in the form of a bar chart. The teacher then calls on the students to explain their reasoning, based on the distribution of their responses.

- The facilitation-reflection phase:

This phase was developed to present students with contradictory information and ask them to reflect on their existing concepts. To achieve these aims, the teacher presents a scientific demonstration or computer simulation related to the question provided in the first phase, has the students observe the results, encourages them to think about the differences between these results and their existing ideas, and leads the class to consider and discuss the possible reasons for these differences. 
Table 1: Details of each phase of the CACC model

\begin{tabular}{|c|c|c|c|c|c|}
\hline Phase & Goal & & Method & $\begin{array}{l}\text { Limitations of } \\
\text { the method in } \\
\text { a lecture class }\end{array}$ & $\begin{array}{l}\text { Potential benefits } \\
\text { of CACC }\end{array}$ \\
\hline $\begin{array}{l}\text { Elicitation- } \\
\text { External- } \\
\text { isation }\end{array}$ & \begin{tabular}{|l|} 
Elicit students' \\
existing \\
concepts and \\
promote their \\
awareness \\
thereof
\end{tabular} & \multirow{4}{*}{$\begin{array}{l}\text { Maintain } \\
\text { students' } \\
\text { motiv- } \\
\text { ation to } \\
\text { engage in } \\
\text { learning } \\
\text { in all } \\
\text { phases of } \\
\text { CACC }\end{array}$} & $\begin{array}{l}\text { Questioning } \\
\text { method }\end{array}$ & $\begin{array}{l}\text { Few students can } \\
\text { respond to the } \\
\text { question and only } \\
\text { one student can } \\
\text { respond at any } \\
\text { one time. }\end{array}$ & $\begin{array}{l}\text { All students can provide } \\
\text { their responses } \\
\text { anonymously and } \\
\text { simultaneously so that } \\
\text { everyone can immedi- } \\
\text { ately view the opinions } \\
\text { of the entire class. }\end{array}$ \\
\hline $\begin{array}{l}\text { Facilitation- } \\
\text { Reflection }\end{array}$ & $\begin{array}{l}\text { Present } \\
\text { students with } \\
\text { contradictory } \\
\text { information } \\
\text { and ask them } \\
\text { to reflect on it }\end{array}$ & & \begin{tabular}{|l|} 
Scientific \\
demonstr- \\
ations and \\
discussions
\end{tabular} & $\begin{array}{l}\text { It is difficult to } \\
\text { motivate most } \\
\text { students to } \\
\text { observe scientific } \\
\text { demonstrations } \\
\text { and participate in } \\
\text { the related } \\
\text { discussions. }\end{array}$ & $\begin{array}{l}\text { Students can become } \\
\text { more involved in } \\
\text { observing scientific } \\
\text { demonstrations and } \\
\text { participating in the } \\
\text { related discussions for } \\
\text { knowing the answer to } \\
\text { the questions presented } \\
\text { in the earlier phase. }\end{array}$ \\
\hline $\begin{array}{l}\text { Guidance- } \\
\text { Restructure }\end{array}$ & $\begin{array}{l}\text { Provide } \\
\text { students with } \\
\text { sufficient } \\
\text { knowledge to } \\
\text { make them } \\
\text { better } \\
\text { understand the } \\
\text { concepts }\end{array}$ & & $\begin{array}{l}\text { Lectures } \\
\text { and } \\
\text { guidance }\end{array}$ & $\begin{array}{l}\text { It is difficult to } \\
\text { motivate most } \\
\text { students } \\
\text { sufficiently to pay } \\
\text { attention to the } \\
\text { lecture. }\end{array}$ & $\begin{array}{l}\text { Students would pay } \\
\text { attention to the contents } \\
\text { of the lecture in order to } \\
\text { address their cognitive } \\
\text { conflict resulted from the } \\
\text { contradictions between } \\
\text { their existing knowledge } \\
\text { and the demonstrated } \\
\text { concepts. }\end{array}$ \\
\hline \begin{tabular}{|l|} 
Evaluation- \\
Elaboration
\end{tabular} & $\begin{array}{l}\text { Evaluate } \\
\text { degree of } \\
\text { conceptual } \\
\text { change among } \\
\text { the students' } \\
\text { and have them } \\
\text { elaborate on } \\
\text { their concepts }\end{array}$ & & $\begin{array}{l}\text { Questioning } \\
\text { method }\end{array}$ & $\begin{array}{l}\text { Few students can } \\
\text { respond to the } \\
\text { question and only } \\
\text { one student can } \\
\text { respond at any } \\
\text { one time. }\end{array}$ & $\begin{array}{l}\text { All students can provide } \\
\text { their responses anonym- } \\
\text { ously and simultan- } \\
\text { eously; the teacher can } \\
\text { thus determine whether } \\
\text { or not the students have } \\
\text { achieved the conceptual } \\
\text { change. }\end{array}$ \\
\hline
\end{tabular}

- The guidance-restructure phase:

This phase was developed to provide sufficient knowledge about a learning topic to enable students to construct concepts. To achieve this goal, the teacher gives a lecture about concepts related to a learning topic using a PowerPoint presentation, and leads students to consider why their existing concepts are correct or incorrect.

- The evaluation-elaboration phase:

This phase was developed to evaluate students' conceptual change and allow them to explain their concepts. To achieve these goals, advanced questions relating to the learning topic are presented by the teacher on the large display and the students are asked to respond using their transmitters.

The order of the four phases was not completely fixed, and the teacher was able to conduct them flexibly. For example, the teacher was allowed to repeat the questioning tasks by asking several questions regarding the same target concept in the elicitationexternalisation phase, and then conduct the next three phases. In addition, in the 
elicitation-externalisation phase, if most of the students provided the correct response to the question, the teacher could reduce the discussion time and increase the pace for the other three phases. Furthermore, if most students were unable to provide correct responses in the evaluation-elaboration phase, the teacher was able to return to the guidance-restructure phase and guide the students in their learning regarding the main concepts of the learning topic again.

\section{Research questions}

One of the major aims of the present study was to determine the effects of the CACC model and how it achieved them. Thus, answers to the following research questions were sought:

- Can CACC benefit students' learning of physics concepts?

- How does CACC benefit or not benefit the students' learning of physics concepts?

\section{Methods}

An embedded experimental model of mixed methodology (Creswell \& Plano Clark, 2007) was adopted to address the research questions. This model involved embedding qualitative data within an experimental design (Creswell \& Plano Clark, 2007). Details regarding the participants, learning environment, instruments, design and procedure are described below.

\section{Participants}

Six classes comprising a total of 275 first-year undergraduates (55 females and 220 males) who took the introductory physics course at a public university in northern Taiwan were the participants in this study. All of the participants had taken physics courses at senior high schools and thus had basic knowledge about physics concepts. One class was selected as the experimental group (50 first-year undergraduates) and the other five classes were selected as the comparison group (225 first-year undergraduates).

Only one class was used as the experimental group because the teacher for this group needed to be willing to have his or her classes observed for 9 weeks. Moreover, because CACC is an innovative instructional model, the teacher had to devote time to becoming sufficiently familiar with its application before the intervention in order to be able to apply it smoothly. Consequently, the teacher selected for the experimental group was a member of our research group who had previous experience teaching physics with clickers. Five classes were selected as the comparison group in order to represent various instructions used in university class settings.

\section{The learning environment}

Both of the classrooms for the experimental group and the comparison group were equipped with an overhead projector and a notebook computer. However, a clicker system, PowerClick, was used in the experimental group but not in the comparison group. 


\section{Instruments}

Pre- and post-tests were developed by three experienced physics experts to include questions related to the three learning units ("mechanical energy", "work" and "rotation"). The purposes and the contents of the two tests were different. Regarding the purposes, the pre-test was used to explore the participants' prior knowledge before the intervention, and all of the test contents were what the participants had learnt in high school. The pre-test score was used as the covariance in the following analysis of covariance (ANCOVA) to control for the effects of the prior knowledge on the post-test performance of the two groups. The post-test was used to examine the students' learning performance after the instruction. Regarding the contents, the pre- and posttests were all made of different questions. Both tests included two common types of test in physics learning: a "comprehension test", which comprises comprehension problems used to examine the students' understanding of the physics concepts, and a "calculation test", which comprises calculation problems used to examine not only students' physics comprehension but also their ability in numerical calculations. Both tests were multiple choice questions with each question scored 1 (correct) or 0 (incorrect). Table 2 lists the number of questions and the internal consistency reliability coefficient (KR-20) of each of the pre- and post-tests. Example items from each type of test are provided in Appendix B. Semi-structured interviews were conducted, which aimed at determining the students' perceptions about learning with CACC. All of these interviews were recorded, and sample questions are listed in Appendix C.

Table 2: Number of questions and reliability (KR-20) of each pre- and post-test

\begin{tabular}{|l|c|c|c|c|}
\hline \multirow{2}{*}{} & \multicolumn{2}{|c|}{ Comprehension test } & \multicolumn{2}{c|}{ Calculation test } \\
\cline { 2 - 5 } & $\begin{array}{c}\text { Number of } \\
\text { questions }\end{array}$ & $\begin{array}{c}\text { Reliability } \\
\text { (KR-20) }\end{array}$ & $\begin{array}{c}\text { Number of } \\
\text { questions }\end{array}$ & $\begin{array}{c}\text { Reliability } \\
\text { (KR-20) }\end{array}$ \\
\hline Pre-test & 10 & 0.70 & 10 & 0.72 \\
\hline Post-test & 7 & 0.67 & 8 & 0.69 \\
\hline
\end{tabular}

\section{Design}

The aims of this study were addressed by applying the embedded experimental model of the mixed-method design. Observational records were collected during the experiment and interview data were collected later to help explain the results. A quasiexperimental design that was conducted in a real classroom setting was used in the current study to examine the effects of CACC on the students' understanding of physics concepts. In the quasi-experimental design, the "instructional method" was selected as a between-subjects factor. The experimental group (one class) learning with the CACC model, in which the four phases of CACC model were flexibly conducted depending on the teacher's teaching needs. The comparison group (five classes) learning with common instructional methods, in which the lecture with the slides or scientific demonstrations or oral questioning method, etc. were spontaneously and flexibly used depending on each teacher's teaching needs. The dependent variable of this experiment was the learning performance in the comprehension and calculation tests, the data for which were collected in the post-test phase.

In order to control for factors that might have affected the post-test score of this study, apart from the "instructional method", the learning time and learning contents of the two groups were controlled so that they were as similar as possible. For example, the two groups carried out different instructional methods twice weekly (2 hours for each 
session, 4 hours total) and both groups received a 9-week introductory physics course about "mechanical energy", "work" and "rotation". Moreover, in order to confirm that the two groups were provided with similar learning contents, the teachers participating in this study discussed the teaching schedule for the entire course 3 weeks before the intervention.

\section{Procedure}

The evaluation of the CACC model consisted of the following five phases (Figure 2).

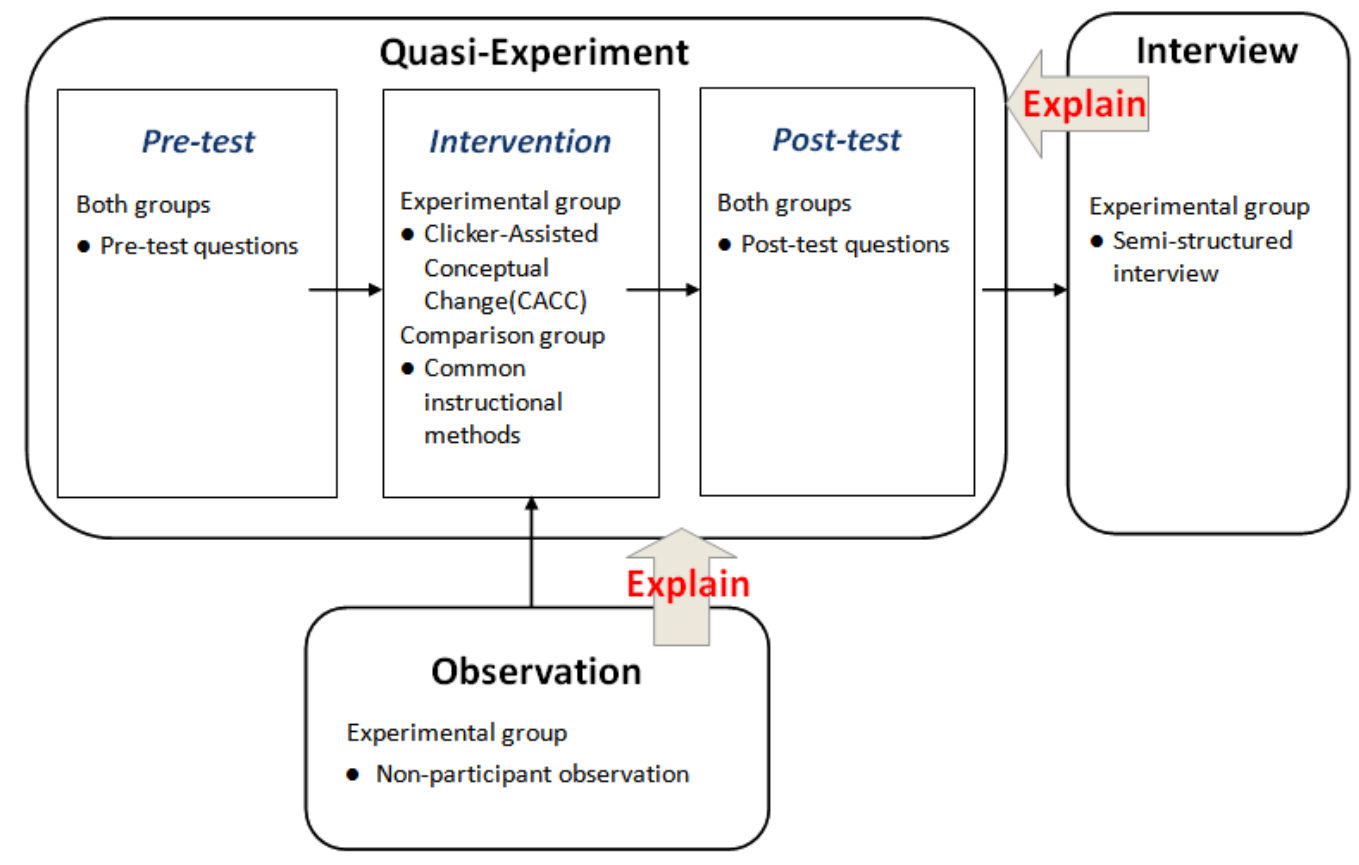

Figure 2: Evaluation procedure for the study

- Pre-test:

This was used to assess both groups' prior knowledge of physics comprehension and calculation 3 days before the intervention. The average time spent on this phase was 30 minutes.

- Intervention:

Both instructional methods, the CACC model for the experimental group and common instructional methods for the comparison group, were carried out twice weekly ( 2 hours for each session, 4 hours in total) throughout the 9 -week course.

- Observation:

During the intervention, non-participant observation of the experimental group was conducted by one of the researchers in order to record the implementation of CACC.

- Post-test:

All participants completed the post-test 3 days after the intervention. The post-test scores were used to represent the students' learning performance of physics comprehension and calculation with the different instructional methods. The average time spent on this phase was about 50 minutes. 
- Interviews:

During the week after the intervention, 25 participants in the experimental group were interviewed using semi-structured questions based on the observational records, in order to further understand their thoughts about learning with CACC. The data collected during the semi-structured interviews were coded according to the method used and the students' identification numbers; for instance, "I09" indicates that the data were collected by interviewing the participant whose student number was 9 .

\section{Results}

One purpose of the current study was to determine the effects of CACC in assisting students' understanding of physics concepts. The means and standard deviations of the pre- and post-test scores for the two groups are given in Table 3.

Table 3: Means and standard deviations of the pre- and post-test scores

\begin{tabular}{|c|l|c|c|c|c|}
\cline { 3 - 5 } \multicolumn{2}{c|}{} & \multicolumn{2}{c|}{ Experimental group } & \multicolumn{2}{c|}{ Comparison group } \\
\cline { 3 - 6 } \multicolumn{2}{c|}{} & Mean & $S D$ & Mean & $S D$ \\
\hline \multirow{2}{*}{ Pre-test } & Comprehension test & 6.86 & 1.48 & 6.75 & 1.97 \\
\cline { 2 - 6 } & Calculation test & 7.28 & 1.83 & 6.28 & 2.34 \\
\hline Post-test & Comprehension test & 3.70 & 1.53 & 2.96 & 1.39 \\
\cline { 2 - 6 } & Calculation test & 5.50 & 1.13 & 5.21 & 1.56 \\
\hline
\end{tabular}

\section{Performance of the comprehension test}

Analysis of covariance (ANCOVA) was used to compare the differences between the two groups' post-test comprehension test scores, while controlling for the respective pre-test scores. A preliminary check was conducted to ensure that there was no homogeneity of the regression slopes $\left(F_{1,271}=2.41, p>0.05\right)$. After adjusting for the pretest scores, there was a significant difference between the two groups regarding their post-test comprehension test scores $\left(F_{1,272}=11.17, p<0.05\right)$. The adjusted mean score of the post-test was higher in the experimental group (3.66) than in the comparison group (2.97).

\section{Performance of the calculation test}

ANCOVA was conducted to compare the differences between the two groups' posttest calculation test scores after confirmation of the non-homogeneity of the regression slopes $\left(F_{1,271}=1.32, p>0.05\right)$. After adjusting for the pre-test scores, there was no significant difference between the two groups $\left(F_{1,272}=1.59, p>0.05\right)$. The adjusted mean score did not differ significantly between the experimental group (5.43) and the comparison group (5.23).

\section{Discussion}

In the current study, the CACC model was developed based on the combination of several important principles relating to the cognitive conflict approach for conceptual change and the educational benefits of clickers. A quasi-experiment was conducted to examine the effects of CACC. The experimental group performed significantly better than the comparison group in the comprehension test after the intervention, but not in the calculation test. The possible reasons for these results in terms of the observational 
records and the results of semi-structured interviews with some of the members of the experimental group are discussed below.

\section{Possible explanations for the better comprehension performance with CACC}

Questioning is seen as a useful method for stimulating students' continuous thinking for conceptual understanding. However, it is difficult to implement successful questioning in traditional lecture classes (Mayer et al., 2009). In the CACC design, with the assistance of clickers, the questioning method can be implemented in class, benefitting students by stimulating and engaging their thinking, thus enhancing their comprehension of the subject.

In CACC, the questioning method (along with the clickers) that was used in the first phase (elicitation-externalisation) is considered a catalyst for engaging the entire class, encouraging all of the students to begin thinking about important concepts, which is often a considerable challenge in traditional classes. In this phase, all of the students were encouraged to think about the questions and then asked to individually express their answers using the clickers. After all of the students' responses were aggregated into a bar chart that showed clearly the distribution of the answers, the teacher asked the students to provide reasons for specific answers. In this way, the students appeared to be separable into several groups according to their choices, and each such group had a sense of commitment to its response (Roschelle \& Pea, 2002). This commitment leads students to play a more active role in the subsequent phases of the process in order to determine whether their answers were correct or incorrect, hence becoming more engaged in thinking about the concept to be learned.

In the experimental group of the current study, the questioning method (along with the clickers) was moderately used (3 to 5 times) in each course depending on the teacher's need. The interview data revealed that the students enjoyed this method and thought that the questioning and answering process could facilitate their engagement in the subsequent learning activities (e.g. I02, I12 and I41). For example, I12 stated: "I like the questioning and answering activity... that tool (transmitter) gives me more opportunity to express my ideas... After I give my answer, I always eagerly want to know if my answer is right or wrong... I think that feeling makes me more involved in the class".

After students' existing concepts had been externalised in the earlier phase and the curiosity to know the correct concept is stimulated, the teacher used the "seeing is believing" method by presenting a demonstration during the demonstration-reflection phase to provide students with opportunities to find the correct answers. Observational records and interview data showed that this can retain or even prolong the engagement of students who were already engaged in the learning process, thus providing them with more opportunities to enhance the occurrence of cognitive conflict.

For example, according to the observational records, when the teacher began to conduct the demonstration, most students rushed to the front of the classroom in order to be able to observe it more closely. Moreover, when the results appeared to be in conflict with their current ideas, most of the students were surprised. The interview data also support the observational data. For example, I17 noted: “... and you should observe the results of the demonstration... It is clear that I felt surprise when what I 
observed was different from what I thought... I would focus more on why these results happened during the lecture that followed".

Some studies have shown that applying clickers can motivate students to think more deeply about important concepts (Draper \& Brown, 2004; Greer \& Heaney, 2004); this was also supported by the findings of the current study. The interview data revealed that in the elicitation-externalisation and evaluation-elaboration phases of the CACC model, the students were forced to think through their responses carefully because they knew that their answers would be presented on the large display, and that they could be picked to express the reasoning behind their responses. For example, I43 stated that "The main difference between this course (introductory physics) and other courses is that I need to make a lot of effort thinking throughout the whole course... I cannot casually select an answer to the question because it would be embarrassing if I cannot give a reasonable explanation for the answer when I am selected (by the teacher)".

\section{Possible explanations for the lack of calculation-test score effects with CACC}

Learning with the CACC did not perform better in calculation test than with other common instructional methods; this may reflect the limitations of the CACC model, and clickers in general. First, the CACC model was designed to enhance students' understanding of physics concepts but not calculations. Therefore, when implementing this model, students have few opportunities to practice how to solve calculation tests. Moreover, clickers do not appear to be suitable for students' responses to calculation questions. Calculation speeds vary widely among students. Clickers can show only one question on a large display; students with a low calculation speed may not have sufficient time to finish the question, or else those with a high calculation speed must wait for the others to finish the question. These limitations of CACC regarding physics calculation may be improved by compromising such that the calculation tests can be provided as homework for the students, and the teacher can take several of these tests as the questions for the first phase of the CACC in the next course. Future studies should examine the usefulness of such a compromising method for CACC.

\section{Other challenges and limitations to the application of the CACC model}

In addition to the limitation regarding physics calculations, the observational and interview data illustrated other challenges and limitations to the application of the CACC model. First, as proposed in the review study undertaken by Kay and LeSage (2009a), there is a challenge related to "coverage", because some students are concerned that using clickers in discussions is too time-consuming (e.g. I05, I33 and I45). For example, I45 stated that "Everything regarding this instructional model is OK, excluding the time... The teacher spends too much time on that (clickers) and Q \& A... That may affect the progress of the course".

Moreover, the interview results echoed other study results indicating that the use of clickers in the questioning method may increase pressure on students (e.g. Kay \& LeSage, 2009a; MacArthur \& Jones, 2008). For example, I33 noted that "Actually, the use of this model makes the course more interesting, but it also makes me feel more pressure in learning... Because, after giving the response with the clicker, I am always afraid of being selected by the teacher to express my ideas." 
Finally, the interview data showed that several students (e.g. I03 and I05) were unhappy in the class and expressed negative attitudes towards CACC. These students responded that they preferred the traditional instructional model to CACC because the traditional approach focuses on explanations of the formulas, which allows them to solve problems more rapidly. For example, I05 stated that "Not everyone likes a course with more interaction between the teacher and students... I hope the teacher can spend more time on introducing and explaining the formulas that will be of more benefit when taking exams." Such doubts and negative perceptions towards CACC should be considered in future revisions and applications of the CACC model.

\section{Conclusions and recommendations}

Two approaches to the application of educational technology have been identified by Mayer (2001). One is a technology-centred approach that emphasises how to apply a new technology in education, whereas the other is a learner-centred approach that emphasises how to aid the learner's cognitive processing with the assistance of a new technology. The current study took the second approach, to develop a clicker-assisted instructional model (known as CACC), based on the combination of the characteristics of clickers and the use of cognitive conflict to aid students in achieving conceptual changes.

Cognitive conflict is a useful approach for promoting conceptual change, which is an important task in science education (Chan et al., 1997; Limon, 2001). However, it is very difficult to implement in lecture classes. With the assistance of clickers, it is assumed that application of the CACC model can address some important but challenging principles for cognitive conflict in lecture classes and can benefit the students' understanding of physics concepts. The results of this study support the assumption that physics comprehension is benefited more by CACC than by the instructional methods used in the comparison group. The findings from direct observation and interviews also revealed that most students felt that the application of CACC allows them to retain and prolong their engagement in the course content, and stimulate them to think more deeply about important concepts.

While these results show that the CACC model has the potential to benefit students' understanding of physics concepts, we also found that its implementation did not significantly improve students' performance of physics calculations, relative to that of the comparison group. Furthermore, the interview data from some of the students also raised some concerns regarding this method, such as course coverage, the pressure associated with the questioning method and the negative attitudes towards a new style of instruction.

Based on the results of this study, we recommend the following guidelines for future applications and research. First, other key science topics should be used as the learning focus of the CACC model to test the benefits of this instructional model (if any) in different contexts. Furthermore, since some students had concerns about time shortages and anxiety when using the model, future work could revise the CACC procedure such as by rearranging the contents of the course and changing the method used to ask questions in class. Finally, in order to better understand the full potential of clickers (Woelk, 2008), more clicker functions could be explored in conjunction with various learning theories. Subsequently, various instructional models could be constructed and examined using a mixed-method approach. 


\section{Acknowledgments}

The authors would like to thank the National Science Council of the Republic of China, Taiwan, for financially supporting this research under Contract No. NSC 98-2628-S008-001-MY3 and NSC 99-2631-S-008-004-. Besides, the authors would also like to thank Professor Chi-Wen Shieh, Jin-Hui Lin and Qiu-Wen Chen for assisting with the development of the comprehension test and calculation test for this study. We also greatly appreciate for the kind assistance and helpful comments of the editor of Australasian Journal of Educational Technology and the anonymous reviewers of this paper. Finally, the authors would like to thank the administration, the teachers and the students of National Central University who participated in this study.

\section{References}

Anderson, R., Anderson, R., VanDeGrift, T., Wolfman, S. \& Yasuhara, K. (2003). Promoting interaction in large classes with computer-mediated feedback. In B. B. Wasson, S. Ludvigsen \& U. Hoppe (Eds), Designing for change in networked learning environments: Proceedings of the International Conference on Computer Support for Collaborative Learning 2003 (pp. 119-123). Bergen, 14-18 June. [verified 11 Sep 2011] http: / / citeseerx.ist.psu.edu / viewdoc/ download?doi=10.1.1.7.9293\&rep=rep1\&type=pdf

Beatty, I. D., Gerace, W. J., Leonard, W. J. \& Dufresne, R. J. (2006). Designing effective questions for classroom response system teaching. American Journal of Physics, 74(1), 31-39. http: / / ajp.aapt.org/resource/1/ajpias /v74/i1/p31_s1

Bunce, D. M., VandenPlas, J. R. \& Havanki, K. L. (2006). Comparing the effectiveness on student achievement of a student response system versus online WebCT quizzes. Journal of Chemical Education, 83(3), 488-493. http: / / dx.doi.org/10.1021/ed083p488

Campbell, J. \& Mayer, R. E. (2009). Questioning as an instructional method: Does it affect learning from lectures? Applied Cognitive Psychology, 23(6), 747-759. http: / / dx.doi.org/10.1002/ acp.1513

Chan, C., Burtis, J. \& Bereiter, C. (1997). Knowledge building as a mediator of conflict in conceptual change. Cognition and Instruction, 15(1), 1-40. http:// dx.doi.org/10.1207/s1532690xci1501_1

Creswell, J. W. \& Plano Clark, V. L. (2007). Designing and conducting mixed methods research. Thousand Oaks, CA: Sage Public Press.

Draper, S. W. \& Brown, M. I. (2004). Increasing interactivity in lectures using an electronic voting system. Journal of Computer Assisted Learning, 20(2), 81-94. http:/ / dx.doi.org/10.1111/ j.13652729.2004.00074.x

Greer, L. \& Heaney, P. J. (2004). Real-time analysis of student comprehension: An assessment of electronic student response technology in an introductory earth science course. Journal of Geoscience Education, 52(4), 345-351. [verified 12 Sep 2011; $3.1 \mathrm{MB}$ ] http: / / nagt.org/files/nagt/jge/ abstracts/Greer_v52n4.pdf

Hancock, T. M. (2010). Use of audience response systems for summative assessment in large classes. Australasian Journal of Educational Technology, 26(2), 226-237. http:/ / www.ascilite.org.au/ajet/ajet26/hancock.html

Hewson, P. W. (1996).Teaching for conceptual change. In D. F. Treagust, R. Duit \& B. J. Fraser (Eds), Improving teaching and learning in science and mathematics. New York: Teachers College Press.

Kay, R. H. \& LeSage, A. (2009a). Examining the benefits and challenges of using audience response systems: A review of the literature. Computers $\mathcal{E}$ Education, 53(3), 819-827. http:/ / dx.doi.org/10.1016/j.compedu.2009.05.001 
Kay, R. \& LeSage, A. (2009b). A strategic assessment of audience response systems used in higher education. Australasian Journal of Educational Technology, 25(2), 235-249. http: / / www.ascilite.org.au/ajet/ajet25/kay.html

Kearney, M. (2004). Classroom use of multimedia-supported predict-observe-explain tasks in a social constructivist learning environment. Research in Science Education, 34(4), 427-453. http: / / dx.doi.org/10.1007/ s11165-004-8795-y

Lantz, M. E. (2010). The use of "clickers" in the classroom: Teaching innovation or merely an amusing novelty? Computers in Human Behavior, 26(4), 556-561. http: / / dx.doi.org/10.1016/j.chb.2010.02.014

Lee, G. \& Kwon, J. (2001). What do you know about students' cognitive conflict: A theoretical model of cognitive conflict process. In Proceedings of 2001 AETS Annual meeting (pp. 309-325). Costa Mesa, 18-21 January.

Limon, M. (2001). On the cognitive conflict as an instructional strategy for conceptual change: A critical appraisal. Learning and Instruction, 11(4-5), 357-380. http: / / dx.doi.org/10.1016/S09594752(00)00037-2

Liu, T. C., Liang, J. K., Wang, H. Y. \& Chan, T. W. (2003). The features and potential of interactive response system. In K. T. Lee \& K. Mitchell (Eds), Proceedings of the International Conference on Computers in Education 2003 (pp. 315-322). Hong Kong, 2-5 December. http: / / citeseerx.ist.psu.edu / viewdoc/ download?doi=10.1.1.105.9585\&rep=rep1\&type=pdf

Liu, T. C. (2007). Teaching in a wireless learning environment: A case study. Educational Technology \& Society, 10(1), 107-123. http:/ / www.ifets.info/journals/10_1/11.pdf

Liu, T. C. (2010). Developing simulation-based computer assisted learning to correct students' statistical misconceptions based on cognitive conflict theory, using "correlation" as an example. Educational Technology \& Society, 13(2), 180-192.

http: / / www.ifets.info/journals/13_2/15.pdf

Liu, T. C., Lin, Y. C. \& Kinshuk (2010). The application of Simulation Assisted Learning Statistics (SALS) for correcting misconceptions and improving understanding of correlation. Journal of Computer Assisted Learning, 26(2), 143-158. http: / / dx.doi.org/10.1111/j.13652729.2009.00330.x

MacArthur, J. R. \& Jones, L. L. (2008). A review of literature reports of clickers applicable to college chemistry classrooms. Chemistry Education Research and Practice, 9(3), 187-195. http:/ / dx.doi.org/10.1039/B812407H

Mayer, R. E. (2001). Multimedia learning. New York: Cambridge University Press.

Mayer, R. E., Stull, A., DeLeeuw, K., Almeroth, K., Bimber, B., Chun, D., Bulger, M., Campbell, J., Knight, A. \& Zhang, H. (2009). Clickers in college classrooms: Fostering learning with questioning methods in large lecture classes. Contemporary Educational Psychology, 34(1), 5157. http: / /dx.doi.org/10.1016/j.cedpsych.2008.04.002

Palmer, D. H. (2003). Investigating the relationship between refutational text and conceptual change. Science Education, 87(5), 663-684. http: / / dx.doi.org/10.1002 / sce.1056

Palmer, D. (2005). A motivational view of constructivist-informed teaching. International Journal of Science Education, 27(15), 1853-1881. http:/ / dx.doi.org/10.1080/09500690500339654

Paschal, C. B. (2002). Formative assessment in physiology teaching using a wireless classroom communication system. Advances in Physiology Education, 26(1-4), 299-308. http: / / advan.physiology.org/ content/ 26/4/299.full

Perkins, K., Adams, W., Dubson, M., Finkelstein, N., Reid, S., Wieman, C. \& LeMaster, R. (2006). PhET: Interactive simulations for teaching and learning physics. The Physics Teacher, 44(1), 1823. http:/ /link.aip.org/link/phteah/v44/i1/p18/s1/html 
Posner, G. J., Strike, K. A., Hewson, P. W. \& Gertzog, W. A. (1982). Accommodation of a scientific conception: Toward a theory of conceptual change. Science Education, 66(2), 211-227. http:/ / dx.doi.org/10.1002/ sce.3730660207

Roschelle, J. \& Pea, R. (2002). A walk on the WILD side: How wireless handhelds may change computer-supported collaborative learning. International Journal of Cognition and Technology, 1(1), 145-168. http: / / dx.doi.org/10.1075/ijct.1.1.09ros

Siau, K., Sheng, H. \& Nah, F. (2006). Use of classroom response system to enhance classroom interactivity. IEEE Transactions on Education, 49(3), 398-403. http: / / dx.doi.org/10.1109/TE.2006.879802

Sung, Y. T., Chang, K. E., Lee, Y. H. \& Yu, W. C. (2008). Effects of a mobile electronic guidebook on visitors attention and visiting behaviors. Educational Technology $\mathcal{E}$ Society, 11(2), 67-80. http://www.ifets.info/journals/11_2/7.pdf

Sharma, M. D., Khachan, J., Chan, B. \& O'Byrne, J. (2005). An investigation of the effectiveness of electronic classroom communication systems in large lectures. Australasian Journal of Educational Technology, 21(2), 137-154. http: / / www.ascilite.org.au/ajet/ ajet21/sharma.html

Woelk, K. (2008). Optimizing the use of personal response devices (clickers) in large-enrollment introductory courses. Journal of Chemical Education, 85(10), 1400-1405. http: / / dx.doi.org/10.1021/ed085p1400

Vosniadou, S. \& Vamvakoussi, X. (2006). Examining mathematics learning from a conceptual change point of view: Implications for the design of learning environments. In L. Verschaffel, F. Dochy, M. Boekaerts \& S. Vosniadou (Eds), Instructional psychology: Past, present and future trends (pp.55-70). Sixteen Essays in Honour of Erik De Corte. London: Elsevier.

\section{Appendix A}

\section{An example showing how CACC was applied in the course}

The elicitation - externalisation phase

At the beginning of the course, after briefly introducing the relationship between "Simple Harmonic Oscillation" and "Moment of Inertia", the teacher displays a multiple choice question about "Simple Harmonic Oscillation" on the large display. The question is as follows: "There are two bodies with the same mass, one is a slender rod with length $\mathrm{L}$ (a physical pendulum), and the other one is a simple pendulum (consists of a pendulum bob and a mass-less string) with the same length L. Which one has a shorter oscillating period for small oscillation?" Then the teacher explains the meaning of the question and asks the students to provide their answers individually using handheld transmitters. After all of the students have provided their answers, the teacher shows the distribution of students' responses, which is presented in the form of a bar chart on the large display, but does not announce the answer to the question. In order to further externalise students' ideas, the teacher selects students who provided different answers and asks each of them to explain the reasons for their responses.

The facilitation - reflection phase

After the end of the discussion in the earlier phase, and in order to foster cognitive conflict in students with the incorrect concepts or confirm the ideas of those with the right answers, the teacher shows a computer simulation that shows two bodies, one of which is a slender rod with length and the other a simple pendulum with the same length $\mathrm{L}$ (i.e., the same situation as in the question used in the elicitation phase). Before playing the simulation, the teacher repeats the question from the earlier phase and reminds the students to carefully observe the simulation. The teacher then asks all of the students to confirm that the length and mass of the two bodies are the same. The 
teacher plays the simulation three times and asks the students "Does the result agree with your choice in the earlier phase? Why or why not?" After using the computer simulation, the teacher asks several questions to lead students to think about the differences between the results of the simulation and their ideas, such as: "What do you think based on your observations?" "What are the reasons for the results? And please try to explain them." The teacher then selects students who provided wrong responses to the question in the elicitation phase.

The guidance - restructure phase

After a discussion about the differences between the students' responses and the results of the simulation, the teacher presents the learning contents related to "Simple Harmonic Oscillation" and "Moment of Inertia" using a PowerPoint presentation to provide students with a more structured and clearer understanding of these concepts. After the lecture, the teacher leads students to think about the reasons for the results of the simulation in the earlier phase of the lecture.

The evaluation - elaboration phase

Finally, to confirm whether most of the students have understood the concepts correctly, the teacher presents an advanced question on the large display, as follows: "What is the length ratio of the rod and simple pendulum that results in a same-period oscillation?" The students are also asked to answer this question using their handheld transmitters, and the teacher shows the correct answer and the distribution of answers. If most students provide the correct response, the teacher continues to the next topic; if not, the teacher returns to the earlier phase to introduce and explain the main concepts again.

\section{Appendix B}

\section{Example items from the comprehension and calculation pre-tests}

An example item from the comprehension test (* indicates the correct answer):

A yo-yo is initially at rest on a horizontal surface. A
string is pulled in the direction shown in the figure.
Assume there is sufficient friction for the yo-yo to roll
without slipping. In what direction will the yo-yo rotate
and move?
(A) Move to the right with no rotation
(B) Move to the left and rotate anticlockwise
(C) Move to the left and rotate clockwise
(D) Move to the right and rotate clockwise
(E) Move to the right and rotate anticlockwise*

An example item from the calculation test ( ${ }^{*}$ indicates the correct answer):

An object of mass $5.0 \mathrm{~kg}$ is moving with a speed of $20 \mathrm{~m} / \mathrm{s}$. How much work is required to make the object reach a final speed of $40 \mathrm{~m} / \mathrm{s}$ ?
(A) $750 \mathrm{~J}$
(B) $1000 \mathrm{~J}$
(C) $1500 \mathrm{~J}$
(D) $3000 \mathrm{~J}^{\star}$
(E) $8000 \mathrm{~J}$ 


\section{Appendix C}

\section{Sample questions from the semi-structured interview}

1. Do you think that learning with the CACC can motivate you to engage in the course? Why or why not?

2. Do you think that learning with the CACC can motivate you to pay more attention to what you should learn in the course? Why or why not?

3. Do you think that learning with the CACC can motivate you to continue thinking about the learning topics of the course? Why or why not?

4. Did you have any notable experiences or thoughts when learning with the CACC?

5. How did you feel about learning introductory physics with the CACC? Did you like it? Why or why not?

6. Based on your learning experiences of the past 9 weeks, please state some of the benefits and shortcomings of learning with the CACC.

Authors: Yi-Chun Lin, PhD candidate, Graduate Institute of Learning \& Instruction, National Central University, Taoyuan, Taiwan. Email: 961407001@cc.ncu.edu.tw

Dr Tzu-Chien Liu (corresponding author), Professor and Director, Graduate Institute of Learning \& Instruction, National Central University, Taoyuan, Taiwan.

Email:1tc@cc.ncu.edu.tw

Dr Ching-Chi Chu, Assistant professor, Department of Physics, National Central University, Taoyuan, Taiwan. Email: cchu@phy.ncu.edu.tw

Please cite as: Lin, Y.-C., Liu, T.-C. \& Chu, C.-C. (2011). Implementing clickers to assist learning in science lectures: The Clicker-Assisted Conceptual Change model.

Australasian Journal of Educational Technology, 27(6), 979-996.

http:/ / www.ascilite.org.au/ajet/ajet27/lin.html 